\title{
PERLOKUSI DALAM VIDEO FILOSOFI STOICISM (EKPEKTASI DAN KEBAHAGIAAN) DI CHANNEL YOUTUBE SATU PERSEN
}

\author{
Okta Dwi Ahryani ${ }^{1}$, Asep Purwo Yudi Utomo \\ ${ }^{1}$ Universitas Negeri Semarang, oktadwiahriyani@ students.unnes.ac.id \\ ${ }^{2}$ Universitas Negeri Semarang, aseppyu@ mail.unnes.ac.id
}

\begin{abstract}
ABSTRAK
Setiap tuturan seringkali mengandung maksud lain. Perlokusi merupakan salah satu tindak tutur yang didalamnya mengandung maksud lain. Tindak tutur perlokusi dapat ditemukan dalam sebuah video, salah satunya pada video filosofi stoicism (Ekpektasi dan kebahagiaan) di channel youtube satu persen. Pada penelitian ini, topik yang dikaji adalah mengenai filosofi hidup stoicism yang mana filosofi tersebut memberi dampak bagi pendengar untuk senantiasa berfikir tentang kemungkinan terburuk. Tuturan dalam video tersebut mengandung perlokusi. Tujuandari penelitian ini adalah untuk mengetahui tindak tutur perlokusi dalam video filosofi stoicism (Ekpektasi dan kebahagiaan) di channel youtube satu persen. Objek penelitian ini adalah tuturan dalam video tersebut. Metode yang digunakan adalah metode deskriftif kualitatif. Perolehan data penelitian ini dilakukan dengan teknik simak dan catat. Hasil dari penelitian ini ditemukan enam data yang mengandung perlokusi yang terdiri atas tindak tutur perlokusi untuk memengaruhi, tindak tutur perlokusi mengajak, dan tindak tutur perlokusi permintaan. Dengan membaca penelitian ini diharapkan dapat menambah pengetahuan tentang pragmatik khusunya tindak tutur perlokusi bagi pembaca.
\end{abstract}

Kata Kunci : Pragmatik. Tindak Tutur, Perlokusi, Filosofi, Stoicism

\begin{abstract}
Each utterance often contains other purposes. Perlokusi is one of the speech acts that contains other purposes. Perlokusi's speech acts can be found in a video, one of which is the philosophy video of stoicism (Expectations and happiness) on the one percent YouTube channel. In this research, the topic studied is about the philosophy of life of stoicism, which philosophy has an impact on listeners to always think about the worst possible. The speech in the video contains perlocution. The purpose of this research is to find out the speech acts of percocution in the philosophy video of stoicism (Expectations and happiness) on the one percent youtube channel. The object of this research is the utterance in the video. The method used is a qualitative descriptive method. The data collection of this research was carried out by listening and note taking techniques. The results of this study found six data containing perlocutionary speech consisting of speech actuations to influence, speech actuating speech invocations, and act of speech demanding. By reading this research it is hoped that it can increase knowledge about pragmatics especially in the act of speech telling for readers.
\end{abstract}

Keyword(s): Pragmatik, Speech Acts, Perlokusi, Philosophy, Stoicism

\section{DOI: https://doi.org/10.31943/bi.v6i1.80}

How to Cite:

Okta Dwi Ahriyani, \& Purwo Yudi Utomo, A. (2021). PERLOKUSI DALAM VIDEO FILOSOFI STOICISM (EKPEKTASI DAN KEBAHAGIAAN) DI CHANNEL YOUTUBE SATU PERSEN. Bahtera Indonesia; Jurnal Penelitian Bahasa Dan Sastra Indonesia , 6(1), 27-34. https://doi.org/10.31943/bi.v6i1.80

\section{PENDAHULUAN}

Emosi yang kita rasakan merupakan hasil dari ekspektasi kita. Sering kali kita mengekpektasikan sesuatu secara berlebihan, padahal hal yang diekspektasi sering kali berbanding terbalik dengan realita, sehingga hal tersebut berdampak pada psikologis kita. Kita menjadi gelisah, stress, cemas, dan banyak perasaan negatif lainnya. Filosofi hidup stoicism membantu kita untuk mengontrol 
dengan semaksimal mungkin apa yang bisa kita kontrol dan menerima dengan sukarela apa yang diluar kendali kita. Untuk itu kita juga perlu paham tentang hal-hal apa saja yang tidak bisa kita kendalikan, seperti opini orang lain, kondisi saat lahir, dan juga peristiwa alam.

Pada abad 21 ini, perkembangan IPTEK sudah sangat pesat. Salah satu yang berkembang pesat adalah alat komunikasi. Hal tersebut tentu saja memudahkan kita untuk berinteraksi dengan sesama. Komunikasi bertujuan untuk menyampaikan pesan dari penutur kepada mitra tutur. Cabang ilmu linguistik yang mengkaji tentang tuturan adalah pragmatik.

Tindak tutur merupakan hal penting dalam kajian pragmatik. Tindak tutur merupakan dasar bagi analisis topik-topik pragmatik lain seperti pranggapan, perikutan, implikatur, percakapan, prinsip kerja sama, prinsip kesantunan, dan sebagainya. Alasan ditampilkannya istilah tindak tutur adalah bahwa di dalam mengucapkan suatu ekspresi, pembicara tidak semata-mata mengatakan sesuatu dengan mengucapkan ekspresi itu. Berkenaan dengan tuturan, ada tiga jenis tindakan, yaitu lokusi, ilokusi, dan perlokusi.

Dalam artikel ini akan menganalisis mengenai tindak tutur perlokusi pada video filosofi stoicism (ekspektasi dan kebahagiaan). Dalam buku Pokok-Pokok Pragmatik (Rustono : 1999), perlokusi merupakan tuturan yang diucapkan seorang penutur sering memiliki efek atau daya pengaruh (perlocurationary force). Efek yang dihasilkan dengan mengujarkan sesuatu itulah yang oleh Austin (!962:101) dinamakan dengan perlokusi.Tuturan dalam video tersebut termasuk dalam perlokusi karena tuturannya memberi dampak atau efek bagi mitra tutur. Dalam video ini tuturan yang dimaksudkan untuk mempengaruhi mitra tutur.

Terdapat beberapa penelitian yang relevan dari beberapan penelitian tentang tindak tutur perlokusi ini, antara lain Insani \& Sabardila (2016) membahas tentang tindak tutur perlokusi guru dalam pembelajaran bahasa Indonesia kelas XI SMK Negeri 1 Sawit Boyolali, Wijaya, Y. F. (2012) membahas tentang analisis Tindak Tutur Perlokusi dalam Tajuk Rencana Harian Kompas", Aziz, S. R. (2012) membahas tentang Tindak Tutur Lokusi dan Perlokusi dalam Novel Surat Kecil Untuk Tuhan Karya Agnes Davonar, Sutoko, A. (2011) membahas tentang Tindak Tutur Perlokusi Dalam Wacana Lha... Dalah! Pada Surat Kabar Joglosemar Edisi Agustus 2010, Cahyani, I. (2013) membahas tentang aya perlokusi wacana iklan rokok di daerah Surakarta, Asmalini, A., Ngudining, R., \& Supadi, S. membahas tentang analisis tindak tutur perlokusi pada iklan di televisi, Wati, M. (2011) membahas tentang efektivitas tuturan perlokusi pada iklan sampo di trantv, Putra Hardita, R., \& Hum, M. (2019). Membahas tentang Analisis Tindak Tutur Perlokusi Pada 
Iklan Minuman Bersoda, Putra, S. P., \& Yuana, C. (2019) membahas tentang analisis Lokusi Ilokusi Perlokusi dalam Drama Koe Koi, Puspitasari, I. (2012) membahas tentang Tindak Tutur Perlokusi Pada Percakapan Para Tokoh Opera Van Java Di Trans7.

Dari penelitian-penelitian tersebut tentu memiliki perbedaan dan kesamaan. Kesamaannya terletak pada fokus penelitian, sedangkan perbedaannya terletak pada topik yang dikaji. Karena hal tersebut, penelitian ini diharapkan dapat melengkapi hasil penelitian terdahulu, khusunya pada bidang perlokusi.

Penelitian ini dirancang untuk menjembatani komunikasi antara penutur dan mitra tutur. Tujuan dari penelitian ini adalah untuk mendeskripsikan tindak tutur perlokusi yang ada dalam video tersebut. Manfaat dari penelitian ini adalah untuk menambah ilmu tentang tindak tutur perlokusi yang akan dibahas ini.

\section{METODE PENELITIAN}

Metode yang digunakan dalam penelitian ini adalah metode deskriptif kualitatif. Metode ini bertujuan untuk memberikan atau menjabarkan suatu keadaan atau fenomena yang sedang terjadi saat ini dengan menggunakan prosedur ilmiah untuk menjawab permasalahan secara aktual.

Data penelitian ini berupa tuturan yang merupakan tuturan perlokusi atau tuturan yang Program Studi Pendidikan Bahasa dan Sastra Indonesia dapat memberi pengaruh bagi mitra tutur.Sumber data yang digunakan dalam penelitian analisis tindak tutur perlokusi ini yaitu tuturan yang terdapat dalam video "Filosofi Stoicism (Ekspektasi dan Kebahagiaan)" yang diambil dari channel youtube Satu Persen.

Tujuan dari penelitian ini adalah menjelaskan tindak tutur perlokusi yang terdapat dalam video "Filosofi Stoicism (Ekspektasi dan Kebahagiaan)" yang diambil dari channel youtube Satu Persen. Manfaat penelitian ini adalah untuk memberikan pengetahuan dalam bidang pragmatik khususnya dalam tindak tutur perlokusi.

Dalam pengumpulan data, penulis menggunakan teknik simak. Pertama penulis menyimak tuturan yang terdapat dalam video. Setelah itu, penulis mentranskrip setiap tuturan yang termasuk dalam perlokusi kedalam bentuk tulisan. Terakhir, penulis menganalisi setiap tuturan yang termasuk kedalam perlokusi tersebut.

\section{HASIL DAN PEMBAHASAN}

Hasil penelitian ini mencakup tindak tutur perlokusi. Dari analisis yang sudah dilakukan penulis, ditemukan enam data yang mengandung perlokusi yang terdiri atas tindak tutur perlokusi untuk memengaruhi, tindak tutur perlokusi mengajak, dan tindak tutur 
perlokusi permintaan. Hasil dari penelitian tersebutdijabarkan sebagai berikut:

\section{Tindak Tutur Perlokusi Untuk}

\section{Memengaruhi}

Tindak tutur untuk memengaruhi yang dimaksud terdapat pada tuturan berikut ini:

1. "Misal lo ikutan lomba debat, lebih baik lo mikir bakal kalah, bahwa nanti argumen lo bakal dibabat oleh lawan debat lo. Jadi, nanti dipikirin kemungkinan terburuknya."

Maksud dari tuturan di atasadalah saat kita mengikuti lomba hendaknya kita juga berpikir kalau kita juga bakal kalah, sehingga nanti jika memang kalah maka kita tidak akan kecewa dan sebaliknya, jika kita menang kita akan merasa sangat bahagia karena kemenangan tersebut melebihi ekspekatsi kita.

Jadi, tuturan dimaksudkan agar memengaruhi kita untuk selalu bersiap dengan kemungkinan terburuk, sehingga kita tidak terbunuh oleh ekpektasi kita nantinya dan jika hasilnya baik, maka kita akan bahagia karena itu diluar ekspektasi kita. Hal tersebut sesuai dengan filosofi hidup stoicism.

Tuturan tersebut termasuk tindak tutur perlokusi yang efeknya untuk memberi pengaruh bagi kita supaya berpikir tentang kemungkinan terburuk.

\section{2. "Dibandingkan berpikir tentang hal-hal yang positif, aliran stoicism justru}

menganggap jika ekpektasi yang lebih baik adalah ketika kita memiliki ekspektasi yang terburuk dalam membayangkan masa depan.".

Dalam tuturan tersebut menjelaskan jika aliran stoicism menganggap jika lebih baik berekspektasi terburuk dalam membayangkan masa depan. Hal tersebut memengaruhi kita untuk melakukan hal tersebut.

Kenapa? Karena jika kita berpikir tentang hal yang terburuk maka kita tidak akan kaget dengan hasil yang akan kita peroleh nantinya. Misal, dimasa depan kita akan kalah maka kita akan biasa saja karena kita sudah bersiap untuk kemungkinan terburuk. Begitupun sebaliknya, jika dimasa depan kita akan menang, maka kemenangan tersebut tentunya akan sangat berharga bagi kita. Karena itulah, penurut memengaruhi kita untuk selalu berekspektasi terburuk untuk masa depan.

Maka data nomor 3 juga merupakan perlokusi. Dari tuturan tersebut bermaksud memengaruhi kita supaya selalu siap dengan apapun yang akan terjadi

\section{Tindak Tutur Perlokusi Mengajak}

Tindak tutur perlokusi mengajak terdapat pada tuturan berikut ini:

1. "Ekspektasi yang diciptakan manusia emang melalui proses yang kayak tadi, 


\section{proses ini dinamakan proses pre-} meditation yaitu proses dimana lo harus memikirkan hal-hal terburuk.

Data 4 menjelaskan tentang proses premeditation yaitu proses dimana kita harus memikirkan hal-hal terburuk.

Dari tuturan tersebut kita diajak untuk memikirkan hal-hal terburuk yang tentunya sesuai dengan aliran ini. Penutur mengajak kita untuk senantiasa berpikir tentang hal-hal terburuk agar ekspektasi kita tidak mengecewakan kita. Hal tersebut sejalan dengan prinsip aliran ini.

Tuturan tersebut termasuk kedalam tindak tutur perlokusi yang bertujuan untuk mengajak kita untuk memikirkan hal terburuk supaya kita tidak dikecewakan oleh ekspektasi kita sendiri.

\section{Tindak Tutur Perlokusi Permintaan}

Tindak tutur perlokusi permintaan terdapat pada tuturan berikut ini:

1. Pas lo bangun pagi, coba lo bayangin dulu nih. Misalnya, lo bakalan lomba gitu, ah lomba hari ini kayakya gue bakalan kalah. Misal lo mau ujian, ah paling nilai ujian gue kali ini jelek. Habis itu lo tanyain pada diri lo sendiri.

Pada tuturan mengandung perlokusi yang maksudnya meminta kita untuk membayangkan sesuatu. Tuturan tersebut menjelaskan jika dalam melakukan sesuatu kita harus membayangkan dulu kemungkinan terburuknya kemudian menanyakan pada diri kita masing-masing. Jadi misal, saat ujian kita mendapat nilai jelek, kita tanyakan pada diri kita sendiri, memang kenapa kalau kita dapet nilai jelek? Oh paling kita dimarahin orang tua, setelah dimarahin orang tua kita jadi berpikir untuk belajar lebih giat lagi, sehingga nilai kitabesoknya membaik dan tentunya hal tersebut dapat dijadikan pelajaran. Meskipun hal itu terkesan pesimis, justru suasana yang diciptakan dalam diri kita positif, karena kita jadi fokus kepada proses bukan hasil.

2. "Jadi diawal lo harus selalu memikirkan semua possibility negatif, yang mungkin bakal terjadi pada diri lo hari itu.

\section{Pada "lo harus selalu memikirkan} possibility negatif" mengandung perlokusi. Hal tersebut meminta kita supaya kita memikirkan possibility atau kemungkinan negatif dari setiap tindakan kita.

Seperti yang kita ketahui, kita sering kali berekspektasi tentang sesuatu yang baik-baik saja. Saat melakukan suatu hal kita pasti berpikir kalau ini memang hal terbaik. Sehingga pada akhirnya, saat hasil yang kita dapat tidak sesuai kita akan merasa kecewa. Karena itulah penutur meminta kita untuk selalu memikirkan tentang possibility negatif, supaya pada akhrinya kita tidak merasa kecewa. 
3. "Pernah ngga lo mau melakukan sesuatu dan lo punya gambaran bahwa sesautu itu bakal berjalan dengan baik, karena sesuatu itu adalah hal yang udah lo siapin dari lama, udah lo itung-itung semuanya dan ya udah lo berekspektasi ngga ada hal yang ngeganggu ekpektasilo itu."

Dari tuturan tersebut termasuk perlokusi permintaan.Kita diminta untuk berpikir tentang sesuatu yang pernah kita ekspektasikan dengan baik, namun hasilnya justru berbanding terbalik. Jadi, tuturan itu termasuk dalam pelokusi karena mmeberi efek bagi kita, yaitu meminta kita untuk melakukan permintaan penutur.

Hasil penelitian ini melengkapi hasil penelitian Syaiful Reza Aziz yang berjudul "Tindak Tutur Lokusi dan Perlokusi dalam Novel Surat Kecil Untuk Tuhan Karya Agnes Davonar”. Hal yang dilengkapi dari penelitian sebelumnya adalah objek penelitiannya yang berbentuk karya sastra yang berjenis prosa.

Untuk mengaitkan dan membandingkan penelitian Perlokusi dalam Video Filosofi Stoicism (Ekspektasi dan Kebahagiaan)" di Channel Youtube Satu Persen, penulis membandingkannya dengan penelitian terdahulu, yaitu penelitian yang dilakukan oleh Syaiful Reza Aziz dengan judul “Tindak Tutur Lokusi dan Perlokusi dalam Novel Surat Kecil Untuk Tuhan Karya
Agnes Davonar" dan penelitian yang dilakukan oleh Ary Indah Mustikasari dalam penelitiannya yang berjudul "Tindak Tutur Pelokusi dalam Perdagangan Jamu di Daerah Stasiun Balapan.

Antara penelitian ini dengan penelitian yang dilakukan oleh Ary Indah Mustikasari terdapat kesamaan, kesamaan tersebut diantaranya: 1) Metode dan teknik pengumpulan data yang digunakan sama, yaitu metode deskriptif kualitatif dan teknik simak. 2) Mengkaji bidang yang sama, yaitu tindak tutur perlokusi. Perbedaan penelitian ini dengan penelitian yang dilakukan oleh Ary Indah Mustikasari terletak pada pembahasannya, pembahasan pada penelitian Ary Indah Mustikasari terbagi menjadi tujuh kelompok, yaitu tindak tutur perlokusi mendorong mitra tutur menganjurkan, Tindak tutur perlokusi meyakinkan, Tindak tutur perlokusi mengalihkan, Tindak perlokusi mendorong mitra tutur memuji, Tindak tutur perlokusi mengurangi ketegangan, Tindak tutur perlokusi menarik perhatian, Tindak perlokusi mengilhami, sedangkan untuk penelitian ini terbagi menjadi tiga kelompok, yaitutindak tutur perlokusi untuk memengaruhi, tindak tutur perlokusi mengajak, dan tindak tutur perlokusi permintaan.

Antara penelitian ini dengan penelitian yang dilakukan oleh Syaiful Reza Aziz 
juga memiliki persamaan dan perbedaan.

Persamaannya terletak pada bidang kajian, yaitu perlokusi dan metode yang digunakan, yaitu metode deskriptif kualitatif. Selain itu, pembahasan dalam penelitian Syaiful Reza Aziz juga terdapat kelompok tindak tutur perlokusi untuk memengaruhi yang mana dalam pembahasan penelitian ini juga terdapat kelompok tersebut.

Perbedaannya terletak pada objek kajiannya, penelitian ini objek kajiannya adalah Perlokusi dalam Video Filosofi Stoicism (Ekspektasi dan Kebahagiaan)" di Channel Youtube Satu Persen, sedangkan penelitian Syaiful Reza Aziz objek kajiannya adalah Tindak Tutur Lokusi dan Perlokusi dalam Novel Surat Kecil Untuk Tuhan Karya Agnes Davonar.

\section{PENUTUP}

\section{Simpulan}

Berdasarkan hasil analisis yang sudah penulis lakukan, penulis menemukan jika data-data tersebut mengandung perlokusi. Dari data analisis tersebut ditemukan 6 tuturan yang mana semuanya mengandung perlokusi yang terdiri atas dua tindak tutur perlokusi untuk memengaruhi, satu tindak tutur perlokusi mengajak, dan dua tindak tutur perlokusi permintaan.

\section{DAFTAR PUSTAKA}

Andhini, D. (2019). Tindak Tutur Lokusi, Ilokusi, dan Perlokusi Dalam Dialog Film Yowis Ben: Kajian Pragmatik. Disertasi. Universitas Airlangga.

Asmalini, A., Ngudining, R., \& Supadi, S. Analisis Tindak Tutur Perlokusi pada Iklan di Televisi. Disertasi. Universitas Bengkulu.

Aziz, S. R. (2012). Tindak Tutur Lokusi dan Perlokusi dalam Novel Surat Kecil Untuk Tuhan Karya Agnes Davonar. Disertasi. Universitas Muhammadiyah Surakarta.

Cahyani, I. (2013). Daya perlokusi wacana iklan rokok di daerah Surakarta. Disertasi. Universitas Muhammadiyah Surakarta. 
Hakim, A. R. (2011). Tindak Tutur Perlokusi pada Komik Kilonjy. Com. Disertasi. Universitas Negeri Semarang.

Hanifah, N., Wendra, I. W., \& Merdhana, I. N. (2014). Nilai Pendidikan Karakter Pada Bentuk Tindak Tutur Lokusi, Ilokusi, dan Perlokusi dalam Novel Astral Astria Karya Fira Basuki. Jurnal Pendidikan Bahasa Dan Sastra Indonesia Undiksha, 2(1).

Ilham, M. (2019). Penerapan Tindak Tutur Lokusi, Ilokusi, dan Perlokusi najwa Shihab Pada Tayangan Mata Najwa: Kajian Pragmatik. Disertasi. Universitas Airlangga Surabaya.

Insani, E. N., \& Sabardila, A. (2016). Tindak tutur perlokusi guru dalam pembelajaran bahasa Indonesia kelas XI SMK Negeri 1 Sawit Boyolali. Jurnal Penelitian Humaniora, 17(2), 176-184.

Putra Hardita, R., \& Hum, M. (2019). Analisis Tindak Tutur Perlokusi Pada Iklan Minuman Bersoda Ditelevisi. Disertasi. Universitas Muhammadiyah Surakarta.

Putra, S. P., \& Yuana, C. (2019). Analisis Lokusi Ilokusi Perlokusi dalam Drama Koe Koi. MEZURASHII: Journal of Japanese Studies, 1(1).

Puspitasari, I. (2012). Tindak Tutur Perlokusi Pada Percakapan Para Tokoh Opera Van Java Di Trans7. Disertasi Universitas Muhammadiyah Surakarta.

Sutoko, A. (2011). Tindak Tutur Perlokusi Dalam Wacana Lha... Dalah! Pada Surat Kabar Joglosemar Edisi Agustus 2010. Disertasi, Universitas Muhammadiyah Surakarta.

Rustono. (1999). Pokok Pokok Pragmatik. Semarang: CV IKIP Semarang Press.

Umaroh, L., \& Kurniawati, N. (2017). Dominasi Ilokusi dan Perlokusi dalam Transaksi Jual Beli. Lensa, 7(1), 21-34.

Wati, M. (2011). Efektivitas Tuturan Perlokusi pada Iklan Sampo di TransTV. Disertasi. Universitas Muhammadiyah Surakarta. 